\title{
Development of Gold Nanoparticle-Doped Activated Carbon Sorbent for Elemental Mercury
}

Jorge Rodríguez-Pérez, M. Antonia López-Antón*, Mercedes Díaz-Somoano, Roberto García, M. Rosa Martínez-Tarazona

Instituto Nacional del Carbón (CSIC), Francisco Pintado Fe, 26, 33011, Oviedo, Spain

*Corresponding author:

Phone: +34 985119090

Fax: +34985297662

Email:marian@incar.csic.es 


\begin{abstract}
The control of mercury $(\mathrm{Hg})$ from coal-fired power plants by adsorption in solid sorbents is an attractive way to reduce $\mathrm{Hg}$ emissions. In this study a commercial activated carbon (Norit RB3) was impregnated with gold nanoparticles for the retention of $\mathrm{Hg}$ in gas phase, with the intention to explore their potential to be regenerated in future investigations. The activated carbon (RB3) was impregnated with different gold contents using polyvinyl alcohol (PVA) and tetrakis (hydroxymethyl)phosphonium chloride (THPC) in order to compare the performance of these two methods. Gold particles of $\sim 5 \mathrm{~nm}$ were obtained in the carbonaceous support for low gold contents $(0.1 \%)$. With comparative purposes of sorbent behaviour, the $\mathrm{Hg}^{0}$ retention capacity was evaluated in a lab-scale device in an $\mathrm{O}_{2}+\mathrm{N}_{2}$ atmosphere. Although the $\mathrm{Hg}$ retention capacities of these sorbents were similar by the two methods, a higher efficiency was achieved with THPC, being in some cases $80 \%$. The results showed that the use of THPC is a promising means for dropping gold $(0.1 \%)$ to make carbonaceous sorbents for use in $\mathrm{Hg}$ capture.
\end{abstract}

Keywords: mercury, gold, coal combustion, activated carbons 


\section{Introduction}

Coal is a chemically complex substance that contains many trace elements including $\mathrm{Hg}$. The combustion of coal can result in this element being released from power stations with potentially harmful consequences for human health and the environment ${ }^{1}$. In fact, coal combustion power plants are the largest anthropogenic source of $\mathrm{Hg}$ emissions. For this reason, a number of national governments and organizations have already implemented, or are in the process of implementing, legislative measures aimed at the control of $\mathrm{Hg}$ emissions. On March 16, 2011, the Environmental Protection Agency (EPA) of the United States (U.S.) ${ }^{2}$ proposed the first national standard to reduce mercury and other toxic air pollution from coal and oil-fired power plants, whereas the European Union's (E.U.) mercury strategy ${ }^{3}$ provides the basis of the E.U. position for the international discussion of $\mathrm{Hg}$ within the context of the United Nations Environment Programme (UNEP).

At the high temperatures of power station boilers, the $\mathrm{Hg}$ in the coal is converted and/or dissociated within the furnace and is released as $\mathrm{Hg}^{0}$, which is then transported by flue gases. When these gases are cooled and due to interactions between $\mathrm{Hg}^{0}$ and other combustion products, $\mathrm{Hg}^{0}$ is partially transformed into oxidized mercury $\left(\mathrm{Hg}^{2+}\right)$ and particle-bound mercury $\left(\mathrm{Hg}_{\mathrm{p}}\right) . \mathrm{Hg}^{2+}$ and $\mathrm{Hg}_{\mathrm{p}}$ are species that may be retained by different gas cleaning devices, flue gas desulphurization (FGD) plants and in particulate control systems installed in the power stations. However, and although different approaches are under development, it is very difficult to remove $\mathrm{Hg}^{0}$ in the typical air-pollution control devices.

Several studies on the retention of $\mathrm{Hg}$ from flue gases by activated carbons, particularly activated carbons impregnated with sulphur, chloride and iodine, have been published $^{4-10}$. Activated carbon injection is currently considered as the most promising 
technology for $\mathrm{Hg}$ removal from the point of view of efficiency and reliability but the operating costs are high ${ }^{4}$. Moreover, the injection of activated carbons that are later retained in the particle control devices, compromises the quality of fly ashes for future applications. For these reasons, the development of other technologies remains one of the main objectives of scientific research.

A sorbent can capture $\mathrm{Hg}$ via amalgamation, physical adsorption, chemical adsorption, and/or chemical reaction. Noble metal sorbents can capture $\mathrm{Hg}$ via amalgamation $^{11-12}$. The amalgamation of $\mathrm{Hg}$ and gold $(\mathrm{Au})$ is well known, as mercury has been used in mining for years to extract Au. However, the reverse process, the use of $\mathrm{Au}$ to capture $\mathrm{Hg}$ from flue gases has not received due attention. An example of the application of sorbents based on $\mathrm{Hg}-\mathrm{Au}$ amalgamation is the project $\mathrm{MerCap}^{\mathrm{TM}}$ (Mercury Control Adsorption Process) ${ }^{13}$ which is currently being tried out at two coalfired utilities. The general concept of $\mathrm{MerCap}^{\mathrm{TM}}$ is to place fixed Au-coated structures into a flue gas stream to adsorb the $\mathrm{Hg}$ and then thermally regenerate the sorbent and recover the Hg. The disadvantage of this technology is that high amounts of Au are needed. This problem can be avoided by developing sorbents from highly efficient amalgam-dispersing Au nanoparticles, which is the aim of the present work.

The preparation of materials with Au nanoparticles has already been carried out to obtain catalysts for different applications ${ }^{14-16}$. However, there is a lack of knowledge concerning the application of such materials to coal combustion gas cleaning. The activity of the catalysts has been shown to depend greatly on both the method of preparation and on the support, prompting a search for alternative preparative methods other than deposition-precipitation ${ }^{17}$. Important questions regarding the use of nanoparticles include finding a way to stabilize them to avoid their aggregation into large clusters and how to control their spatial positions in the materials ${ }^{18}$. Methods 
based on the reduction of a chloroauric acid solution with tetrakis(hydroxymethyl)phosphonium chloride (THPC) or polyvinyl alcohol (PVA)/NaBH 4 are suitable procedures, due to the smaller particle sizes (3-6 nm) and the narrower distributions obtained ${ }^{19-20}$. Furthermore the particle diameter can be easily adjusted by altering certain preparation parameters (reduction agent, concentration of reagents ${ }^{17}$, temperature ${ }^{21}$, etc).

The final objective of the present research work is to develop carbonaceous sorbents that contain $\mathrm{Au}$ nanoparticles able to amalgamate with $\mathrm{Hg}$. A sorbent is being developed with the intention of be regenerated and used in the flue gas stream at the end of the coal combustion cycle where most of $\mathrm{Hg}^{2+}$ may already have been retained, assuming that it will be used in a power plant in where DeNox, particles control and desulphurization devices are operating. This paper only focuses on the development of sorbents and compares their performance in the basic conditions. To attain this goal, the study was carried out using an activated carbon of high surface area as the support for $\mathrm{Au}$ nano-particles to obtain a sorbent for retention of $\mathrm{Hg}^{0}$ that, potentially, could subsequently be regenerated. Two methods of preparation, both of which prevent the aggregation of $\mathrm{Au}$ into large particles, were tested. $\mathrm{Hg}$ retention capacity and efficiency was evaluated in relation to different amounts of $\mathrm{Au}$ in the carbonaceous material.

\section{Experimental}

\subsection{Materials and preparation procedures}

A commercial activated carbon (peat-based, steam-activated) called Norit RB3 was used as support. The activated carbon was ground to a size of $0.2-0.5 \mathrm{~mm}$ and was characterized by various methods. The ash and sulphur contents were determined by LECO automatic analyzers. The porous texture was determined by $\mathrm{N}_{2}$ and $\mathrm{CO}_{2}$ 
adsorption isotherms at 77 and $273 \mathrm{~K}$, respectively. Pore size distributions (PSDs) from the nitrogen adsorption data were obtained by applying the non local density functional theory (NLDFT) procedure ${ }^{22-23}$, using software provided by Quantachrome.

Au-loaded RB3 sorbents were prepared by two methods based on the formation of Au colloids ${ }^{19}$ :

i) $\mathrm{PVA} / \mathrm{NaBH}_{4}$ method: $3.09 \mathrm{~mL} \mathrm{HAuCl}_{4} \cdot 3 \mathrm{H}_{2} \mathrm{O}(0.127 \mathrm{M})$ was dissolved in $28 \mathrm{~mL} \mathrm{H}_{2} \mathrm{O}$ and mixed with $0.3 \mathrm{~mL}$ PVA (polyvinilalcohol) $(2 \% \mathrm{wt})$. Afterwards, $0.32 \mathrm{~mL} \mathrm{NaBH} 4$ $(0.05 \mathrm{M})$ was dropped and mixed by stirring. The solution immediately turned red and Au sol was formed. $80 \mathrm{mg}$ RB3 was then added to the solution which was shaken for 2 h. Next the sorbent was filtered, washed and dried. Finally the PVA was removed by warming under an inert atmosphere $\left(3 \mathrm{~h} / 350^{\circ} \mathrm{C} / 100 \mathrm{~mL} / \mathrm{min} \mathrm{Ar}\right)$.

ii) $\mathrm{THPC} / \mathrm{NaOH}$ method: $4 \mathrm{~mL} \mathrm{H}_{2} \mathrm{O}$ was mixed with $0,12 \mathrm{~mL} \mathrm{NaOH}(0.2 \mathrm{M}) .0,16 \mathrm{~mL}$ of a THPC (tetrakis(hydroxymethyl)phosphonium chloride) solution was then added under stirring. Next $3.09 \mathrm{~mL} \mathrm{HAuCl}{ }_{4} \cdot 3 \mathrm{H}_{2} \mathrm{O}(0.127 \mathrm{M})$ was introduced into the solution as a result of which the solution turned brown and $\mathrm{Au}$ sol was formed. A solution of 80 mg RB3 and $8 \mathrm{~mL} \mathrm{H}_{2} \mathrm{O}$ (agitated for $15 \mathrm{~min}$ in an ultrasonic bath) was then added to the $\mathrm{Au}$ sol. The final solution was agitated for $2 \mathrm{~h}$, after which the sorbent was filtered, washed and dried. The THPC was removed by warming under an inert atmosphere (3 $\left.\mathrm{h} / 350^{\circ} \mathrm{C} / 100 \mathrm{~mL} / \mathrm{min} \mathrm{Ar}\right)$.

\subsection{Analysis of the activated carbon impregnated with Au nanoparticles}

The $\mathrm{Au}$ distribution and speciation on the Au-impregnated activated carbon surface were analyzed by transmission electron microscopy (TEM) and X-ray photoelectron spectroscopy (XPS), respectively. The BET surface area was determined by means of volumetric adsorption of nitrogen at $77 \mathrm{~K}$. The meso- and macroporosity 
was analyzed by mercury porosimetry. The quantity of Au retained in the sorbent was determined by analyzing the $\mathrm{Au}$ in the solution after impregnation by inductively coupled plasma mass spectrometry (ICP-MS). Oxidation with $\mathrm{H}_{2} \mathrm{O}_{2} \quad 30 \%$ v/v was performed to remove any traces of PVA and THPC in the solution. The average particle diameters of the Au particles on the carbon support were determined by TEM analysis.

\subsection{Experimental device for $\mathrm{Hg}$ retention experiments}

The laboratory device used for $\mathrm{Hg}$ retention is shown in Figure 1. It consists of a glass reactor heated by a furnace. $80.0 \mathrm{mg}$ of sorbent was placed inside the reactor. The volume of the sorbent bed was $113 \mathrm{~mm}^{3}$. The $\mathrm{Hg}^{0}$ in gas phase was obtained from a permeation tube in a $\mathrm{N}_{2}$ atmosphere and passed through the sorbent bed in $\mathrm{O}_{2}+\mathrm{N}_{2}$ stream of $0.5 \mathrm{~L} \mathrm{~min}^{-1}$. The $\mathrm{O}_{2}$ concentration of the atmosphere was $12.6 \% \mathrm{v} / \mathrm{v}$. The concentration of $\mathrm{Hg}$ in the $\mathrm{O}_{2}+\mathrm{N}_{2}$ stream was $100 \mu \mathrm{g} \mathrm{m}{ }^{-3}$. The gas lines were heated to avoid condensation. The temperature of the sorbent was kept at $120^{\circ} \mathrm{C}$. A continuous Hg emission monitor (VM 3000) was used to obtain the Hg adsorption curves.

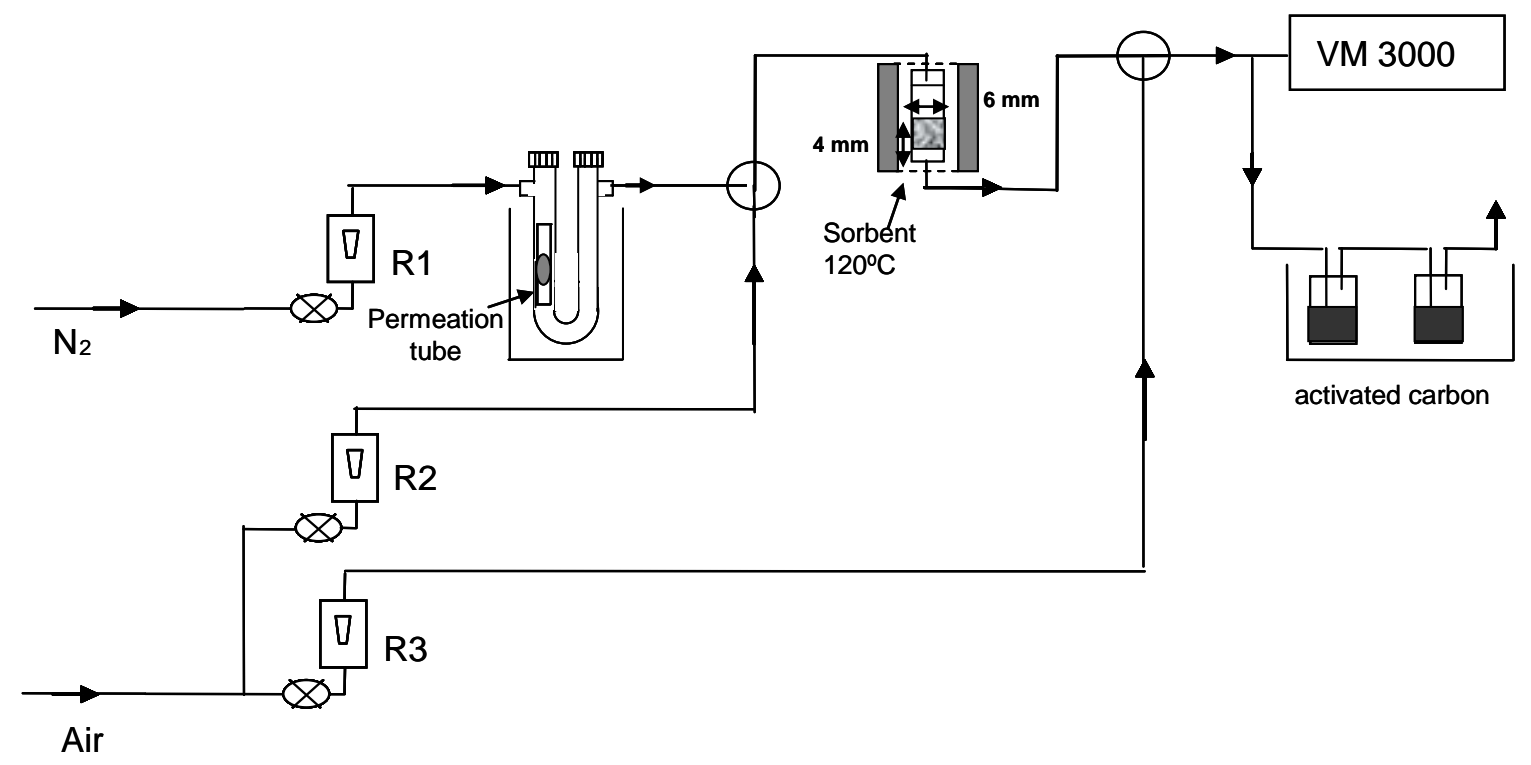

Figure 1. Schematic diagram of experimental device for mercury retention 


\section{Results and discussion}

\subsection{Characterization of the support}

The sulphur content in the activated carbon is $0.43 \% \mathrm{wt}$. The porous texture of the RB3 has been described in detail in a previously published work ${ }^{24}$. It should also be mentioned that its nitrogen adsorption isotherms belong to type I of the BDDT classification, with type IV playing only a minor role. The values for the surface area, total pore volume $\left(\mathrm{V}_{\mathrm{t}}\right)$, equivalent micropore suface area $\left(\mathrm{V}_{\mathrm{DReq}}\right)$ obtained by fitting the Dubinin-Radushkevich (DR) equation and micropore volume $\left(\mathrm{V}_{\text {micDR }}\right)$ are presented in Table 1. $\mathrm{CO}_{2}$ adsorption isotherms were performed in the relative pressure interval of 0 0.03, where only the narrowest micropores are filled. The results for the micropore volume by fitting the DR equation and the equivalent micropore surface area are shown in Table 2. As can be seen, the equivalent micropore surface area value obtained from DR with $\mathrm{CO}_{2}$ is lower than that obtained from the $\mathrm{N}_{2}$ isotherms. This is due to the welldeveloped microporosity of RB3 that has pores which $\mathrm{CO}_{2}$ is unable to fill. The study by NLDFT revealed that this activated carbon possesses a pore distribution where most of the pores range between 5 and $20 \AA$.

\subsection{Au deposition on RB3 support}

RB3 sorbents with contents of $\mathrm{Au}$ ranging from 0.05 to $5 \mathrm{wt} \%$ were prepared using both the PVA and THPC methods. The amount of Au theoretically present on the sorbent when all the element present in solution was coated was denoted Au calculated, while the amount of $\mathrm{Au}$ analyzed in the sorbent after deposition, was designated $\mathrm{Au}$ deposited (Table 3). As can be observed, the amount of Au supported, regardless of the preparation method, was quantitative for low contents of $\mathrm{Au}(0.05$ and $0.1 \%)$. However, 
when the $\mathrm{Au}$ content increases (1-5\%), the amount of $\mathrm{Au}$ on each support varies depending on the method of preparation (Table 3). The Au coating was almost $100 \%$ effective with the THPC method, as opposed to $30 \%$ using the PVA. This is because, unlike THPC, PVA is a colloidal protector with very low water solubility. It therefore prevents the Au from totally dissolving and causes the non-quantitative immobilization of $\mathrm{Au}$ on the support.

The BET surface area of Au-loaded RB3, regardless of the preparation method or the amount of Au deposited, was similar to that of the raw activated carbon (Table 1), i.e. from 1139 to $1166 \mathrm{~m}^{2} \mathrm{~g}^{-1}$. This indicates that no textural changes occurred during the deposition of the Au. The meso- and macroporosity of the samples are presented in Figure 2, which shows the distribution of these two types of porosity for the RB3 activated carbon before and after the deposition of $0.1 \%$ Au by means of PVA and THPC. The cumulative intrusion curves hardly show any variation for the mesopores of lower size.

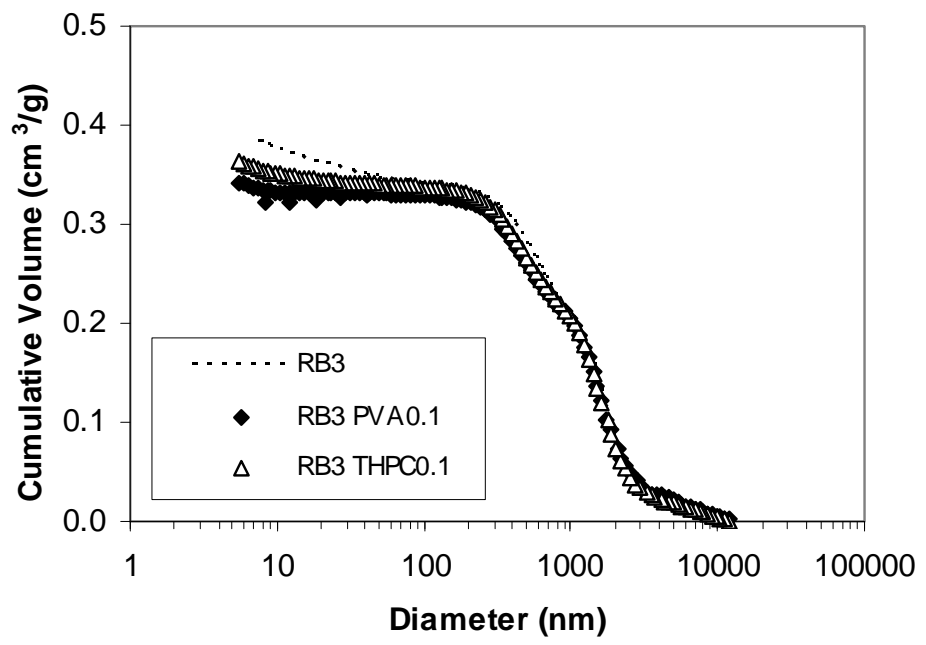

Figure 2. Pore size distribution by mercury porosimetry of the raw RB3 and RB3 samples with $0.1 \%$ gold, using PVA and THPC. 
According to TEM analysis, the average size of the Au particles, regardless of the preparation method applied (PVA or THPC), was smaller in the samples with lower contents of $\mathrm{Au}(4.9 \pm 1.7 \mathrm{~nm})$ than in those with high levels $(8.4 \pm 2.1 \mathrm{~nm})$. Figures 3 and 4 show TEM micrographs of RB3 with 0.1 and $0.6 \%$ Au obtained by the PVA method. In these micrographs it can be observed that the distribution of $\mathrm{Au}$ particles is more homogeneous for low $\mathrm{Au}$ contents. Moreover, an increase in the concentration of $\mathrm{Au}$ widens the range of particle sizes: Figure 5 shows a micrograph of the material loaded with 5\% Au by the THPC method, where particle sizes range from 4 to $18 \mathrm{~nm}$.

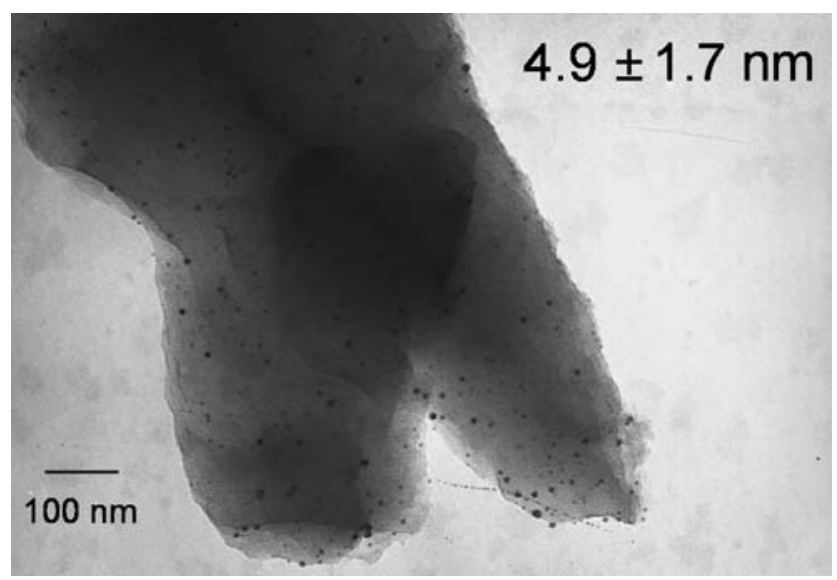

Figure 3. TEM micrograph and average gold particle diameter of RB3 PVA0.1.

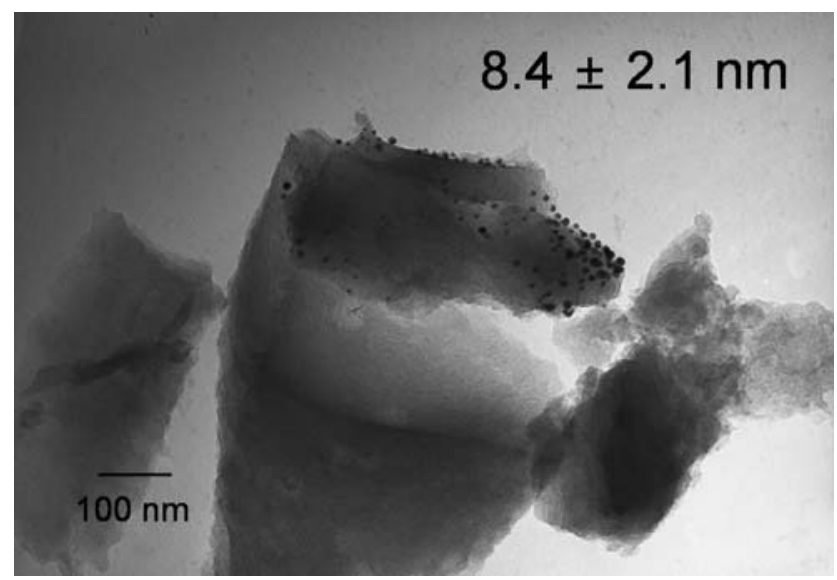

Figure 4. TEM micrograph and average gold particle diameter of RB3 PVA0.6. 


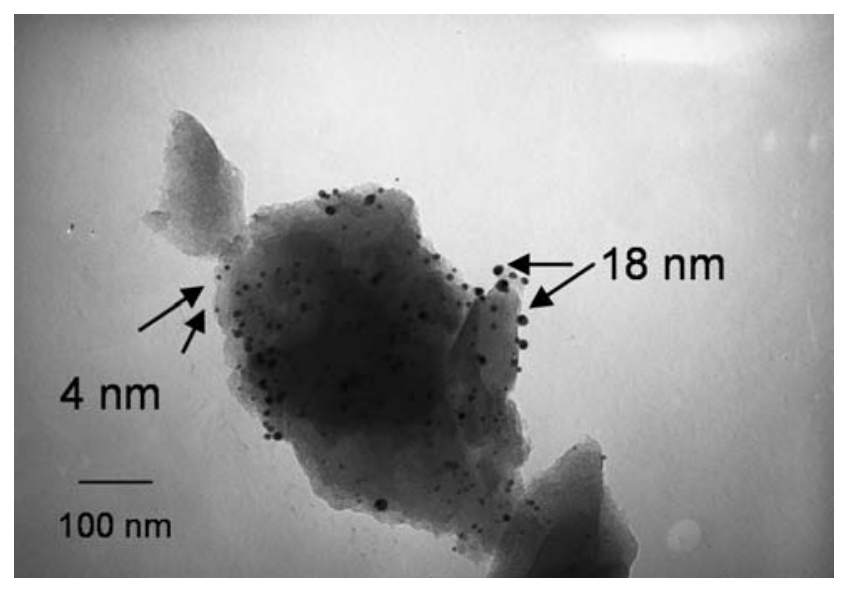

Figure 5. TEM micrograph and average gold particle diameter of RB3 THPC5.

Characterization of the Au-loaded activated carbon by XPS showed two Au $4 \mathrm{f}$ peaks corresponding to the binding energy of metallic $\mathrm{Au}(84.0$ and $87.7 \mathrm{eV})$. Figure 6 represents RB3 PVA0.3. The absence of oxidized Au, at least within the XPS detection limit, makes the methods of impregnation tested for carbonaceous sorbents suitable for elemental gold deposition.

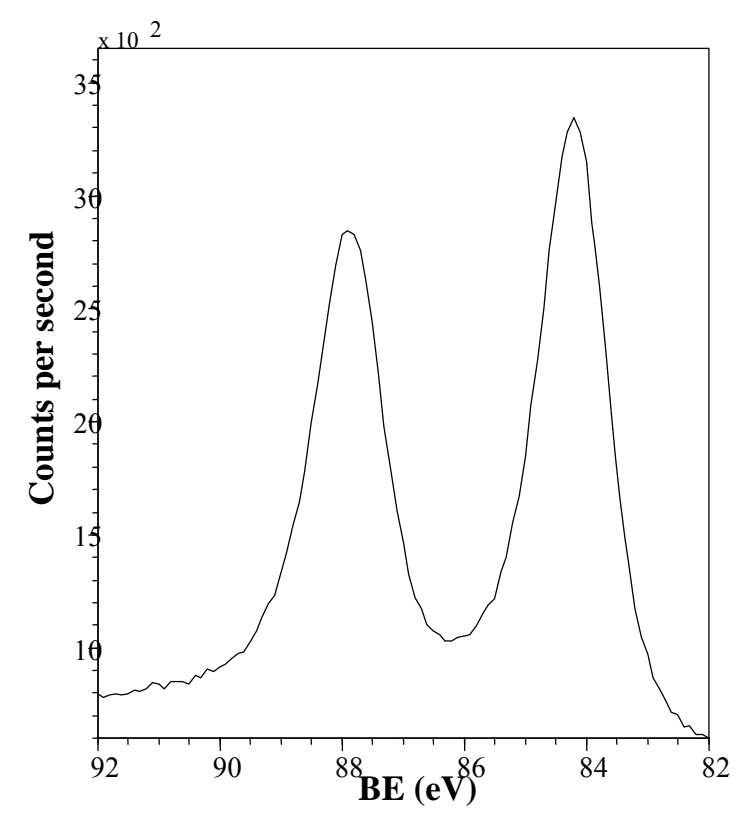

Figure 6. XPS spectrogram of RB3 PVA0.3. Au 4f with peaks corresponding to $\mathrm{Au}(0)$. 


\subsection{Hg retention on $\mathrm{RB} 3$ impregnated with Au nanoparticles}

The $\mathrm{Hg}$ adsorption curves and $\mathrm{Hg}$ retention capacities for the raw RB3 and the coated Au-RB3 samples are given in Figure 7 and Table 4, respectively. The curves represent the outlet/inlet $\mathrm{Hg}$ concentration ratio $\left(\mathrm{C}_{\text {out }} / \mathrm{C}_{\text {in }}\right)$ versus time. The $\mathrm{Hg}$ retention capacities were calculated at two points, the breakthrough time $\left(\mathrm{t}_{\mathrm{b}}\right)$ and after $4320 \mathrm{~min}$ of retention (Table 4). The breakthrough time is defined as the time at which a sample retains $\mathrm{Hg}$ with $100 \%$ efficiency $\left(\mathrm{C}_{\text {out }} / \mathrm{C}_{\text {in }}=0\right)$. As can be seen in Figure 7 , the saturation point of the sorbent $\left(\mathrm{C}_{\text {out }} / \mathrm{C}_{\text {in }}=1\right)$ (only achieved with raw RB3) was not reached in any of the samples impregnated with $\mathrm{Au}$, at least during the 4320 min in question. This time (4320 min) was chosen as being a reasonable experimental duration of time for comparing the behaviour of the different sorbents under similar conditions. The concentration of $\mathrm{Hg}$ retained (retention capacity) was calculated as the area between the curve and the background $\left(\mathrm{C}_{\text {out }} / \mathrm{C}_{\mathrm{in}}=1\right)$ for both, $\mathrm{t}_{\mathrm{b}}$ and the $4320 \mathrm{~min}$ (Table 4$)$. The validity of this calculation method was confirmed by a post-retention analysis of the sorbents using an automatic mercury analyzer (AMA). Table 4 shows the results obtained by the mathematical method $(\mathrm{MM})$ and the AMA at the final of the experiments (4320 min).

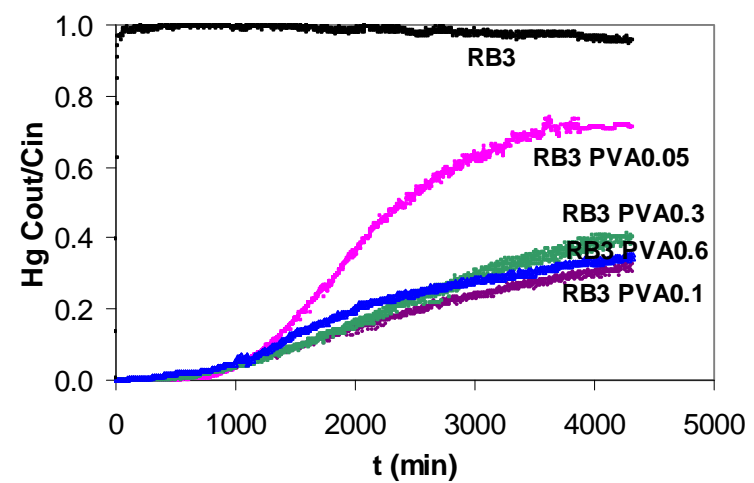

(a)

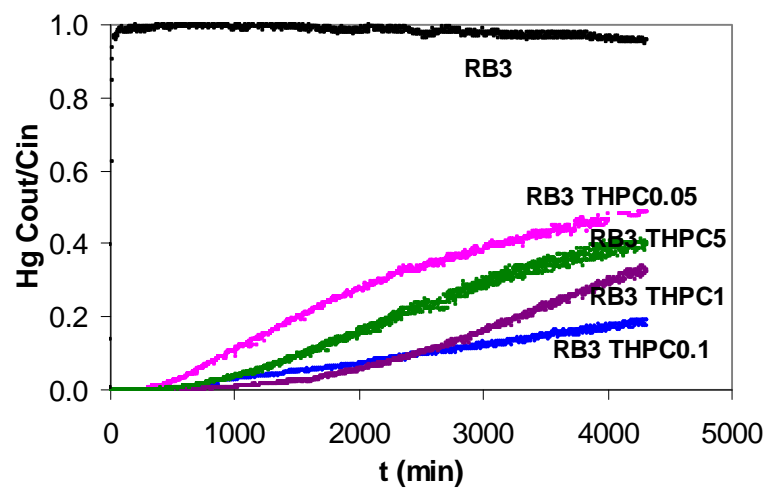

(b) 
Figure 7. Curves of mercury adsorption in raw RB3 and RB3 samples with different gold contents, obtained by (a) PVA and (b) THPC.

The continuous Hg analyzer employed in this study (VM 3000) is only able to detect $\mathrm{Hg}^{0}$. Although $\mathrm{Hg}^{0}$ was the species passing through the sorbent in these experiments, the possibility that some oxidation of $\mathrm{Hg}$ may have taken place on the sorbent bed cannot ruled out. Therefore, to ensure that all the Hg leaving the sorbent was $\mathrm{Hg}^{0}$, a study of $\mathrm{Hg}$ speciation in the RB3 samples was carried out. For this purpose, the gas at the sorbent bed outlet was collected in an Ontario Hydro impinger train device, instead of the VM 3000 analyzer. This method is able to distinguish between $\mathrm{Hg}^{0}$ and $\mathrm{Hg}^{2+}$. The results obtained clearly show that no oxidation of $\mathrm{Hg}^{0}$ took place during the retention experiments in $\mathrm{O}_{2}+\mathrm{N}_{2}$ atmosphere for all the sorbents doped with gold.

The retention capacity of $\mathrm{Hg}^{0}$ increased considerably when the RB3 activated carbon was impregnated with $\mathrm{Au}$ (Figure 7). The $\mathrm{Hg}$ retention capacity of the raw RB3 was approximately $10 \mu \mathrm{g} \mathrm{g}^{-1}$ while the Au-loaded RB3 samples exhibited retention values higher than $3 \mathrm{mg} \mathrm{g}^{-1}$ after 4320 min of experiment with an efficiency of $84 \%$ (Table 4). This behaviour is similar to the performance of activated carbon RB3 impregnated with sulphur (commercial activated carbon Norit RBHG3) which was specifically prepared for $\mathrm{Hg}$ capture (Table 4). However an increase in Au content does not always favour the retention of $\mathrm{Hg}$. Mercury retention capacities of $100 \%$ efficiency ranged from 0.4 to $0.7 \mathrm{mg} \mathrm{g}^{-1}$ in the samples prepared using PVA method, while the $\mathrm{Hg}$ retention range for their THPC counterparts was even greater $\left(0.2-0.9 \mathrm{mg} \mathrm{g}^{-1}\right)$ (Table 4). The best result was obtained for RB3 impregnated with Au using the THPC method with $1 \%$ of $\mathrm{Au}$ followed by $0.1 \%$ of $\mathrm{Au}$. As can be observed, in the sorbents prepared 
with PVA, the sample with the highest $\mathrm{Au}$ content $(0.6 \%)$ presents the lowest $\mathrm{Hg}$ retention $\left(0.36 \mathrm{mg} \mathrm{g}^{-1}\right)$ at the breakthrough time $\left(\mathrm{t}_{\mathrm{b}}\right)$. In the THPC samples, Hg retention improves for $\mathrm{Au}$ increases up to $1 \%$, but above this value $\mathrm{Hg}$ retention deteriorates (Table 4). To explain these observations it is worth to remain that $\mathrm{Hg}$ retention depends not only on the $\mathrm{Au}$ content but also on its distribution and particle size. TEM micrographs revealed lower particle diameters and a better distribution for low $\mathrm{Au}$ concentrations $(0.1 \%$, Figures 3-5). However, the formation of gold aggregates corresponds to the highest $\mathrm{Au}$ concentration (Figure 8). Impregnation with the highest amount of $\mathrm{Au}(5 \%)$ may form large-sized aggregates which in turn reduce the accessibility of $\mathrm{Hg}$.

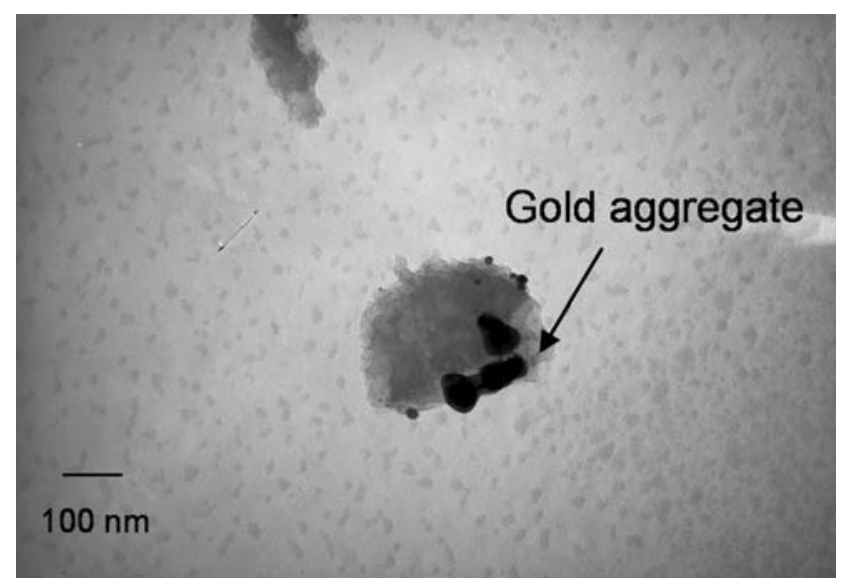

Figure 8. TEM micrograph for RB3 THPC5 showing the formation of aggregates.

Regarding the $\mathrm{Hg}$ retention capacity of the Au-loaded -RB3 samples after 4320 min (Table 4, Figure 7), no significant differences were observed as the Au content increased. Similar $\mathrm{Hg}$ retention capacities $\left(3 \mathrm{mg} \mathrm{g}^{-1}\right)$ were found irrespective of the preparation method. However, the amount of $\mathrm{Au}$ supported has a significant influence on $\mathrm{Hg}$ capture efficiency, with the highest values corresponding to the RB3 samples with $0.1 \% \mathrm{Au}$ (70 and 84\%, for PVA and THPC, respectively). Therefore, retention 
capacities achieved in the sorbents with low $\mathrm{Au}$ contents are greater and the adsorption rates during the amalgamation of $\mathrm{Hg}-\mathrm{Au}$ are higher. The $\mathrm{Hg}$ retention capacity and efficiency of the Au-loaded RB3 samples is comparable to that of the commercial activated carbon RBHG3, which has been specifically designed for $\mathrm{Hg}$ retention at lower temperatures (Table 4, Figure 9). Although the highest $\mathrm{Hg}$ retention at 100\% efficiency corresponds to RBHG3 (1.1 $\left.\mathrm{mg} \mathrm{g}^{-1}\right)$, high $\mathrm{Hg}$ retention capacities can also be observed for some of the samples of RB3 coated with Au (RB3 THPC0.1 and RB3 THPC1).

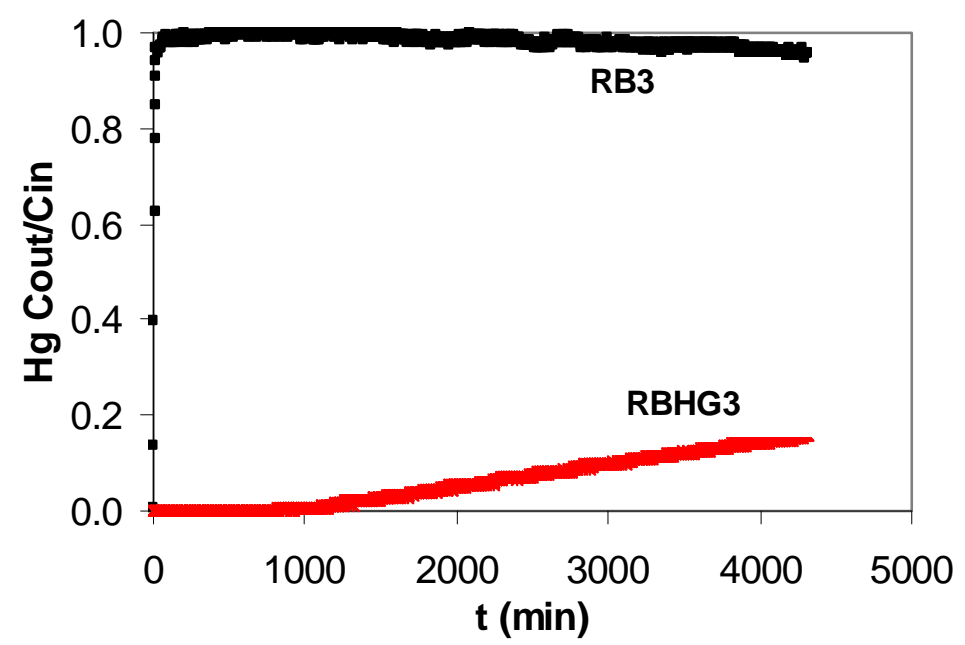

Figure 9. Curves of mercury adsorption in raw RB3 and RBHG3 (activated carbon impregnated with sulphur).

\section{Conclusions}

The evaluation of the performance of nano-dispersed Au loaded activated carbon sorbents in an atmosphere containing just $\mathrm{O}_{2}$ and $\mathrm{N}_{2}$ allowed evaluate the different behaviours of sorbents prepared with various concentrations of $\mathrm{Au}$ and by different methods. The chief factor that determines $\mathrm{Hg}$ retention by Au-loaded active carbons is 
the homogeneity and deposition of the Au particles on the carbonaceous support rather than the amount of gold. Although the quantities of $\mathrm{Hg}$ retained in any given time may be similar, the efficiency of $\mathrm{Hg}$ capture depends mainly on the distribution and accessibility of $\mathrm{Au}$ particles. Nanosized Au particles of $\sim 5 \mathrm{~nm}$ were obtained on the support at low Au contents. In the search for a suitable balance between the amount of $\mathrm{Au}$ employed and the $\mathrm{Hg}$ retained, it can be concluded that the samples with a $0.1 \% \mathrm{Au}$ content are good sorbents for $\mathrm{Hg}$ capture.

Different $\mathrm{Hg}$ adsorption rates were observed with the two $\mathrm{Au}$ impregnation methods used in this study (PVA and THPC), with higher efficiencies generally corresponding to THPC. THPC, which acts both as a reducing agent and as an inhibitor of large particles, offers a very useful method for depositing nanoparticles of $\mathrm{Au}$ with the possibility of being regenerated and tested for $\mathrm{Hg}$ retention on an industrial scale in subsequent investigations.

\section{Acknowledgments}

The authors thank the CSIC (PIF-06-050) and the Spanish Ministerio de Ciencia e Innovación (CTQ2008-06860-C02-01) for financial support.

\section{References}

(1) Zero Hg Global Campaign. Developments at United Nations Environment Programme (UNEP) level. 2009; http://www.zeromercury.org/UNEP developments/ index.html. 
(2) U.S. Environmental Protection Agency (EPA). Proposed rule that set standards to reduce mercury and other toxic air pollution from coal and oil-fired power plants. March 16, 2011; http://www.epa.gov/airquality/powerplanttoxics/pdfs/proposal.pdf

(3) Commisision of the European Communities. Communication from the Commission to the Council and the European Parliament- Community Strategy Concerning Mercury. SEC (2205) 101, 2005; $\underline{\text { http://eur- }}$ lex.europa.eu/LexUriServ/LexUriServ.do?uri=COM:2005:0020:FIN:EN:PDF

(4) Pavlish, J. H.; Sondreal, E. A.; Mann, M. D.; Olson, E. S.; Galbreath, K. C.; Laudal, D. L.; Benson, S. A. Fuel Process. Technol. 2003, 82, 89- 165.

(5) Felsvang, K.; Gleiser, R.; Juip, G.; Nielsen, K. K. Fuel Process. Technol. 1994, 39, 417-430.

(6) Krishnan, S. V.; Gullet, B. K.; Jozewicz, W. Environ. Sci. Technol. 1994, 28, $1506-1512$

(7) Livengood, C. D.; Huang, H. S.; Wu, J. M. Experimental evaluation of sorbents for the capture of mercury in flue gases. Proceedings of $87^{\text {th }}$ Annual Meeting and Exhibition of the Air and Waste Management Association. Cincinnati, Ohio June 19-24, 1994.

(8) Liu, W.; Vidic, R. D.; Brown, T. D. Environ. Sci. Technol. 2000, 34, 154-159.

(9) Vidic, R. D.; Siler, D. P. Carbon. 2001, 39, 3-14.

(10) Granite, E. J.; Pennline, H. W.; Hargis, R. A. Ind. Eng. Chem. Res. 2000, 39, 1020-1029.

(11) Brown, T. D.; Smith, D. N.; Hargis, R. A.; O’Dowd, W. J. J. Air. Waste Manage. Assoc. 1999, 49(6), 628-640.

(12) Yan, T. Y. Ind. Eng. Chem. Res. 1994, 33(12), 3010-3014. 
(13) National Energy Technology Laboratory. 2006; http://www.netl.doe.gov/ technologies/coalpower/ewr/mercury/control-tech/mercap.html.

(14) Biella, S.; Prati, L.; Rossi, M. J. Catal. 2002, 206, 242-247.

(15) Bond, G. C.; Thompson, D. T. Catal. Rev. Sci. Eng. 1999, 41, 319-388.

(16) Schmid, G.; Corain, B. Eur. J. Inorg. Chem. 2003, 17, 3081-3098.

(17) Porta, F.; Patri, L.; Rossi, M.; Coluccia, S.; Martra, G. Catal. Today. 2000, 61, $165-172$.

(18) Chen, X.; Zhao, D.; An, Y.; Zhang, Y.; Cheng, J.; Wang, B.; Shi, L. J. Colloid Interf. Sci. 2008, 322, 414-420.

(19) Önal, Y.; Schimpf, S.; Claus, P. J. Catal. 2004, 223, 122-133.

(20) Demirel-Gülen, S.; Lucas, M.; Claus, P. Catal. Today. 2005, 102-103, 166-172.

(21) Grunwaldt, J-D.; Kiener, C.; Wogerbauer, C.; Baiker, A. J. Catal. 1999, 181, 223-232.

(22) Olivier, J. P.; Conkin, W. P. B.; Szombathely, M. V. Characterization of Porous Solids III (J. Rouquerol, F. Rodríguez-Reinoso, K.S.W. Sing and K.K. Unger, Eds.), Elsevier, Amsterdam, 1994; p.81.

(23) Vishnyakov, A.; Ravikovitch, P. I.; Neimark, A.V. Langmuir. 1999, 15, 87368742.

(24) Lopez-Anton, M. A.; Diaz-Somoano, M.; Fierro, J. L. G.; Martinez-Tarazona, M. R. Fuel Process. Technol. 2007, 88, 799-805. 
Table 1. Surface area, total pore volume, DR equivalent micropore surface area and micropore volume based on $\mathrm{N}_{2}$ adsorption isotherms of activated carbon RB3.

\begin{tabular}{ccccc}
\hline Sorbent & $\begin{array}{c}\text { Surface area } \\
\left(\mathbf{m}^{\mathbf{2}} \mathbf{g}^{-\mathbf{1}}\right)\end{array}$ & $\begin{array}{c}\mathbf{V}_{\mathbf{t}} \\
\left(\mathbf{c m}^{\mathbf{3}} \mathbf{g}^{-\mathbf{1}}\right)\end{array}$ & $\begin{array}{c}\mathbf{S}_{\mathrm{DReq}} \\
\left(\mathbf{m}^{\mathbf{2}} \mathbf{g}^{-\mathbf{1}}\right)\end{array}$ & $\begin{array}{c}\mathbf{V}_{\text {micrDR }} \\
\left(\mathbf{c m}^{\mathbf{3}} \mathbf{g}^{-\mathbf{1}}\right)\end{array}$ \\
\hline $\mathrm{RB} 3$ & 1183 & 0.53 & 1260 & 0.45 \\
\hline
\end{tabular}

Table 2. Micropore volume and equivalent micropore surface area obtained by DR based on $\mathrm{CO}_{2}$ adsorption isotherms of activated carbon RB3.

\begin{tabular}{ccc}
\hline Sorbent & $\begin{array}{c}\mathbf{V}_{\text {micrDR }} \\
\left(\mathbf{c m}^{3} \mathbf{g}^{-\mathbf{1}}\right)\end{array}$ & $\begin{array}{c}\mathbf{S}_{\text {DReq }} \\
\left(\mathbf{m}^{2} \mathbf{g}^{-1}\right)\end{array}$ \\
\hline RB3 & 0.37 & 1009 \\
\hline
\end{tabular}

Table 3. Gold content in the RB3 coated sorbents prepared by PVA and THPC.

\begin{tabular}{ccc}
\hline & $\begin{array}{c}\text { Au calculated } \\
\text { (wt\%) }\end{array}$ & $\begin{array}{c}\text { Au deposited } \\
\text { (wt\%) }\end{array}$ \\
\hline & 0.050 & 0.049 \\
RB3 PVA & 0.10 & 0.09 \\
& 1.0 & 0.33 \\
& 1.9 & 0.59 \\
\hline & 0.051 & 0.050 \\
RB3 THPC & 0.10 & 0.10 \\
& 1.0 & 0.98 \\
& 4.8 & 4.7 \\
\hline
\end{tabular}

Table 4. Mercury retention capacity and efficiency in the RB3 samples.

\begin{tabular}{l|l|c|c|cc|c}
\hline \multirow{2}{*}{ Sorbent } & \multirow{2}{*}{$\begin{array}{c}\mathrm{Au} \\
\% \mathrm{wt}\end{array}$} & \multicolumn{2}{|c|}{ Efficiency $100 \%$} & \multicolumn{3}{c}{$\mathrm{t}=4320 \mathrm{~min}$} \\
\cline { 3 - 7 } & & $\begin{array}{c}\text { Hg retention } \\
\left(\mathrm{mg} \mathrm{g}^{-1}\right)\end{array}$ & $\begin{array}{c}\mathrm{t}_{\mathrm{b}} \\
(\mathrm{min})\end{array}$ & \multicolumn{2}{|c|}{$\begin{array}{c}\text { Hg retention } \\
\left(\mathrm{mg} \mathrm{g}^{-1}\right)\end{array}$} & $\begin{array}{c}\text { Efficiency } \\
(\%)\end{array}$ \\
\cline { 3 - 7 } & & $\mathrm{MM}$ & & $\mathrm{MM}$ & $\mathrm{AMA}$ & \\
\hline RB3 PVA0.05 & 0.05 & $0.66 \pm 0.02$ & 830 & $2.1 \pm 0.4$ & $1.9 \pm 0.3$ & 30 \\
RB3 PVA0.1 & 0.1 & $0.63 \pm 0.01$ & 750 & $2.9 \pm 0.4$ & $2.6 \pm 0.3$ & 70 \\
RB3 PVA0.3 & 0.3 & $0.63 \pm 0.02$ & 750 & $2.8 \pm 0.5$ & $2.7 \pm 0.2$ & 60 \\
RB3 PVA0.6 & 0.6 & $0.36 \pm 0.01$ & 420 & $2.7 \pm 0.3$ & $2.4 \pm 0.3$ & 65 \\
\hline RB3 THPC0.05 & 0.05 & $0.24 \pm 0.01$ & 360 & $2.8 \pm 0.2$ & $2.5 \pm 0.4$ & 50 \\
RB3 THPC0.1 & 0.1 & $0.70 \pm 0.03$ & 860 & $3.1 \pm 0.3$ & $3.0 \pm 0.2$ & 82 \\
RB3 THPC1 & 1 & $0.94 \pm 0.03$ & 1120 & $3.0 \pm 0.2$ & $2.8 \pm 0.3$ & 67 \\
RB3 THPC5 & 5 & $0.53 \pm 0.01$ & 645 & $2.8 \pm 0.2$ & $2.7 \pm 0.3$ & 60 \\
\hline RBHG3 & 0 & $1.1 \pm 0.1$ & 1260 & $3.2 \pm 0.3$ & $3.0 \pm 0.2$ & 84 \\
\hline AMA
\end{tabular}

AMA; automatic mercury analyzer, $\mathrm{MM}$; mathematical method, $\mathrm{t}_{\mathrm{b}}$; breakthrough time 


\section{Figure captions}

Figure 1. Schematic diagram of experimental device for mercury retention

Figure 2. Pore size distribution by mercury porosimetry, of raw RB3 and RB3 samples with $0.1 \%$ gold, using PVA and THPC.

Figure 3. TEM micrograph and average gold particle diameter of RB3 PVA0.1.

Figure 4. TEM micrograph and average gold particle diameter of RB3 PVA0.6.

Figure 5. TEM micrograph and average gold particle diameter of RB3 THPC5.

Figure 6. XPS spectrogram of RB3 PVA0.3. Au 4f with peaks corresponding to Au(0).

Figure 7. Curves of mercury adsorption in raw RB3 and RB3 samples with different gold contents, obtained by (a) PVA and (b) THPC.

Figure 8. TEM micrograph for RB3 THPC5 showing the formation of aggregates.

Figure 9. Curves of mercury adsorption in raw RB3 and RBHG3 (activated carbon impregnated with sulphur). 